\title{
Monoazo and diazo dye decolourisation studies in a methanogenic UASB reactor
}

\author{
R. Brás ${ }^{\mathrm{a}}$, A. Gomes ${ }^{\mathrm{a}}$, M.I.A. Ferra ${ }^{\mathrm{a}}$, H.M. Pinheiro ${ }^{\mathrm{b}}$, I.C. Gonçalves ${ }^{\mathrm{a}, *}$ \\ ${ }^{a}$ Chemistry Department, University of Beira Interior, R. Marquês D'Avila e Bolama, 6200 Covilhã, Portugal \\ ${ }^{\mathrm{b}}$ Centre of Biological and Chemical Engineering, Instituto Superior Técnico, Av. Rovisco Pais, P 1096 Lisbon, Portugal
}

Received 26 February 2004; received in revised form 2 August 2004; accepted 9 August 2004

\begin{abstract}
Mixed anaerobic bacterial consortia have been show to reduce azo dyes and batch decolourisation tests have also demonstrated that predominantly methanogenic cultures also perform azo bond cleavage. The anaerobic treatment of wool dyeing effluents, which contain acetic acid, could thus be improved with a better knowledge of methanogenic dye degradation. Therefore, the decolourisation of two azo textile dyes, a monoazo dye (Acid Orange 7, AO7) and a diazo dye (Direct Red 254, DR254), was investigated in a methanogenic laboratory-scale Upflow Anaerobic Sludge Blanket (UASB), fed with acetate as primary carbon source. As dye concentration was increased a decrease in total COD removal was observed, but the acetate load removal (90\%) remained almost constant. A colour removal level higher than $88 \%$ was achieved for both dyes at a HRT of $24 \mathrm{~h}$. The identification by HPLC analysis of sulfanilic acid, a dye reduction metabolite, in the treated effluent, confirmed that the decolourisation process was due mainly to azo bond reduction. Although, HPLC chromatograms showed that 1-amino-2-naphthol, the other AO7 cleavage metabolite, was removed, aeration batch assays demonstrated that this could be due to auto-oxidation and not biological mineralization. At a HRT of $8 \mathrm{~h}$, a more extensive reductive biotransformation was observed for DR254 (82\%) than for $\mathrm{AO} 7(56 \%)$. In order to explain this behaviour, the influence of the dye aggregation process and chemical structure of the dye molecules are discussed in the present work.
\end{abstract}

(c) 2004 Elsevier B.V. All rights reserved.

Keywords: Azo dyes; Methanogenesis; Colour removal; UASB

\footnotetext{
* Corresponding author. Tel.: +351 75319 730; fax: +35175319730.

E-mail addresses: imscg@ciunix.ubi.pt,imscg@yahoo.com (I.C. Gonçalves).
}

\section{Introduction}

The conversion of organic matter to methane and carbon dioxide in anaerobic processes requires the combined activity of several kinds of bacteria, facultative and obligate anaerobes. The three main groups of bacteria, fermentative, acidogens (acetogenic) and 
methanogens differ significantly in physiology, nutrient requirements, metabolic characteristics and growth rate (McInerney et al., 1980). The methanogens are the key organisms in the production of methane because only they can metabolise acetate and hydrogen to gaseous end products. They require strict anaerobic environments for growth (redox potential values below $-450 \mathrm{mV}$ ) and a limited $\mathrm{pH}$ range of 6-8. They utilize a narrow range of substrates, namely $\mathrm{CO}_{2}, \mathrm{H}_{2}$, formate, methanol, methylamines and acetate, as carbon and/or energy sources and in general their growth rates are lower than those of other anaerobic groups (Stronach et al., 1986). For all this, the methanogenic bacteria are pointed out as the most sensitive microbial group in anaerobic cultures. The acetate is quantitatively the most important precursor of methane during anaerobic degradation of organic matter, preceding $60-70 \%$ of the total methane produced.

Azo dyes are one of the oldest industrially synthesized organic compounds and represent the major group $(60-70 \%)$ of the more than 10,000 dyes currently manufactured (Carliell et al., 1996; Zollinger, 1987). Aside from their negative aesthetic effects, certain azo dyes and their biotransformation products have been shown to be toxic to aquatic life and mutagenic to humans (Brown and Hamburguer, 1987). Azo dyes may be decolourised by cleavage of the azo bond, to which the colour is associated, via anaerobic degradation through an non-specific and presumably extracellular process, in which reducing equivalents from an external electron donor (biologically or chemically generated) are transferred to the dye (Wuhrmann et al., 1980). It has also been reported (Brás et al., 2001), in studies carried out in batch reactors, that azo bond reduction is also performed by a predominantly methanogenic population. The reduction of azo dyes results in the formation of aromatic amines that mostly cannot be metabolised anaerobically, with the exception of a few examples bearing hydroxyl and carboxyl groups, which can be fully degraded under methanogenic conditions (Razo-Flores et al., 1996). The persistent character of aromatic amines is thus dependent on the type and position of substituents on the aromatic rings (PastiGrigsby et al., 1992). Aerobic conditions are preferable for aromatic amine degradation, but it should be noted that some of them could be auto-oxidized to polymeric structures in the presence of oxygen (Kudlich et al., 1999).
The Upflow Anaerobic Sludge Blanket (UASB) reactor design promotes the formation of dense active sludge granules with good settling characteristics and mechanical strength (Lettinga et al., 1980). These structural characteristics of bacterial aggregates and the high biomass retention achieved in the UASB reactor improve the tolerance of anaerobic bacteria to xenobiotic compounds, such as aromatic amines and azo dyes, and promote adaptation of the bacteria to the presence of these molecules (Donlon et al., 1997). Therefore, the UASB reactor, which has proven to be able to treat various industrial wastewaters with high efficiency and stability (Lettinga et al., 1991), was the reactor configuration selected for this study.

The purpose of the present work was to evaluate the performance of a methanogenic laboratory-scale UASB reactor for treating two azo textile dyes, a monoazo dye (Acid Orange 7, AO7) and a diazo dye (Direct Red 254, DR254). The effects of HRT and dye concentration on the anaerobic decolourisation were considered in this study. The azo reduction process was monitored by UV-visible spectrophotometry and highpressure liquid chromatography (HPLC).

\section{Materials and methods}

\subsection{UASB reactor operation}

A 151 Upflow Anaerobic Sludge Blanket (UASB) reactor (height $100 \mathrm{~cm}$, diameter $14 \mathrm{~cm}$ ) was maintained at $37 \pm 2{ }^{\circ} \mathrm{C}$ and seeded with $25 \mathrm{gl}^{-1}$ VSS of anaerobic sludge originating from a full-scale UASB reactor treating paper pulp manufacturing wastewater. The UASB reactor was fed with synthetic wastewater containing basal nutrients, trace elements and sodium acetate as carbon source (1925 $\pm 133 \mathrm{mg} \mathrm{l}^{-1}$ COD 95\% significance level). The feed was stored refrigerated at $4{ }^{\circ} \mathrm{C}$, and fed to the reactor with a peristaltic pump after a period of equilibration to room temperature. In this study, the reactor was operated with two different hydraulic retention times (HRT), namely 24 and $8 \mathrm{~h}$. The biogas production was measured with gas a flowmeter system (Ritter, U.K.).

\subsection{Basal medium}

The basal medium contained $\left(\mathrm{mgl}^{-1}\right) \mathrm{Ca}(\mathrm{OH})_{2}$ 90; $\mathrm{NH}_{4} \mathrm{Cl} 170 ; \mathrm{NaH}_{2} \mathrm{PO}_{4} \cdot 2 \mathrm{H}_{2} \mathrm{O} 48 ; \mathrm{MgCl}_{2} \cdot 6 \mathrm{H}_{2} \mathrm{O}$ 


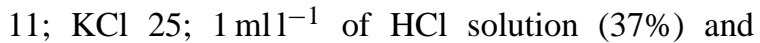
$0.5 \mathrm{mll}^{-1}$ of a trace elements solution containing $\left(\mathrm{mg} \mathrm{l}^{-1}\right) \mathrm{H}_{3} \mathrm{BO}_{3} 100 ; \mathrm{FeCl}_{2} \cdot 4 \mathrm{H}_{2} \mathrm{O}$ 4000; EDTA 2000; $\mathrm{ZnCl}_{2} \cdot 4 \mathrm{H}_{2} \mathrm{O}$ 100; $\mathrm{MnCl}_{2} \cdot 4 \mathrm{H}_{2} \mathrm{O} \quad 50 ; \mathrm{CuCl}_{2} \cdot 2 \mathrm{H}_{2} \mathrm{O}$ 60; $\left(\mathrm{NH}_{4}\right)_{6} \mathrm{MoO}_{7} \cdot 4 \mathrm{H}_{2} \mathrm{O} \quad 180 ; \quad \mathrm{NiCl}_{2} \cdot 6 \mathrm{H}_{2} \mathrm{O} \quad 100$; $\mathrm{Na}_{2} \mathrm{SeO}_{3} \cdot 5 \mathrm{H}_{2} \mathrm{O}$ 200. Sodium bicarbonate was used $\left(6-9 \mathrm{gl}^{-1}\right)$ to neutralise the medium. The basal medium was prepared with tap water and flushed during $15 \mathrm{~min}$ with $\mathrm{N}_{2}$ to drive off dissolved oxygen, before the addition of $\mathrm{Na}_{2} \mathrm{~S}\left(60 \mathrm{mg} \mathrm{l}^{-1}\right)$ to promote more strict anaerobic conditions.

\subsection{Anaerobic activity assay}

The specific methanogenic activity tests were performed in triplicate, in bottles of $250 \mathrm{ml}$ capacity sealed with rubber septa. After washing with buffer phosphate solution $\left(1.28 \mathrm{~g} \mathrm{Na}_{2} \mathrm{HPO}_{4} \mathrm{l}^{-1}\right.$ and $0.42 \mathrm{~g}$ $\mathrm{NaH} 2 \mathrm{PO}_{4} 1^{-1}$ ) in order to remove residual substrate, sludge samples were transferred $\left(2 \mathrm{~g} \mathrm{VSS}^{-1}\right)$ to bottles containing basal mineral medium $(56 \mathrm{ml})$. After $12 \mathrm{~h}$ of incubation at $35 \pm 2{ }^{\circ} \mathrm{C}, 4 \mathrm{ml}$ of an acetate solution $\left(57 \mathrm{~g} \mathrm{l}^{-1} \mathrm{COD}\right)$ were injected and the assay bottles were then flushed with $\mathrm{N}_{2}$ for 15 min and incubated in the dark at $35 \pm 2{ }^{\circ} \mathrm{C}$ with magnetic stirring (100 rpm). Azo dyes were added together with the acetate solution (from 60 to $1800 \mathrm{mg} \mathrm{l}^{-1}$ resulting dye concentration). The OxiTop ${ }^{\circledR}$ Control sensor (WTW, Germany) was used to measure the biogas pressure in the bottle headspace. The specific methanogenic activity was calculated from the slope of the biogas production versus time curve and was expressed as litre of biogas per gram of volatile suspended solids per day $\left(\mathrm{g} \mathrm{g}^{-1} \mathrm{day}^{-1}\right.$ VSS $)$.

\subsection{Analyses}

The colour was measured spectrophotometrically with a Lambda 6 spectrophotometer (Perkin Elmer, U.S.A.) at the maximum visible absorbance wavelength of the dye (482 and $507 \mathrm{~nm}$ for AO7 and DR254, respectively). Absorbance at this wavelength was correlated with dye concentration and used to quantify decolourisation. The samples were previously filtered with microfibre membranes $(1.2 \mu \mathrm{m}$ porosity) and diluted when necessary.

Both dye and metabolite concentrations were followed by HPLC in a Spectra-Physics (U.S.A.) system equipped with a gradient pump, a reversed-phase col- umn RP-18 (i.d. $4.6 \mathrm{~mm}$, length $250 \mathrm{~mm}$, stationary phase particle size $10 \mu \mathrm{m}$ ) and a UV detector at $240 \mathrm{~nm}$. The eluents consisted of a phosphate buffer solution (0.70 g ${ }^{-1} \mathrm{NaH}_{2} \mathrm{PO}_{4}$ and $0.58 \mathrm{~g} \mathrm{l}^{-1} \mathrm{NH}_{4}\left(\mathrm{H}_{2} \mathrm{PO}_{4}\right)$ (A) and methanol (B)). The linear gradient elution ranged from $\mathrm{A} / \mathrm{B}(85 / 15)$ to $\mathrm{A} / \mathrm{B}(20 / 80)$ in 45 min with a flow rate of $1 \mathrm{ml} \mathrm{min}^{-1}$ and $20 \mu \mathrm{l}$ injection volume. The eluents and the samples were previously filtered. The identification of the azo dyes and aromatic amines was achieved by comparison of retention times to those of the respective standards.

The methane content in the gas samples was determined by gas chromatography. The gas chromatograph, HRGC Mega 2 series from Fisons Instruments (U.K.) was equipped with a megabore column $(30 \mathrm{~m} \times$ $53 \mathrm{~mm}$ ) and a divinylbenzene homopolymer as stationary phase. The temperatures of the column, the injector port and the TCD detector were set at 35,85 and $270{ }^{\circ} \mathrm{C}$, respectively. Helium was used as carrier gas with a flow rate of $5 \mathrm{ml} \mathrm{min}^{-1}$ and the injection volume was $150 \mu \mathrm{l}$.

The values of $\mathrm{pH}$, volatile suspended solids (VSS) and soluble chemical oxygen demand (COD) in liquid samples were determined according to Standard procedures (APHA, 1992).

\subsection{Azo dyes and metabolites}

The azo dyes chosen for the present study (Fig. 1) were C.I. Acid Orange 7 (Anaranjado Anthosin 35L) in the form of an aqueous solution with dye content of $39 \%(\mathrm{~m} / \mathrm{m})$ which also includes formic acid, and C.I. Direct Red 254 (Rojo Fastusol 50L) in the form of aqueous solution with dye content of $65 \%(\mathrm{~m} / \mathrm{m})$ purchased from BASF (Germany). Both dyes were dissolved in the basal media in a range of concentrations between 60 and $300 \mathrm{mg}^{-1}$. Acid Orange 7 purified

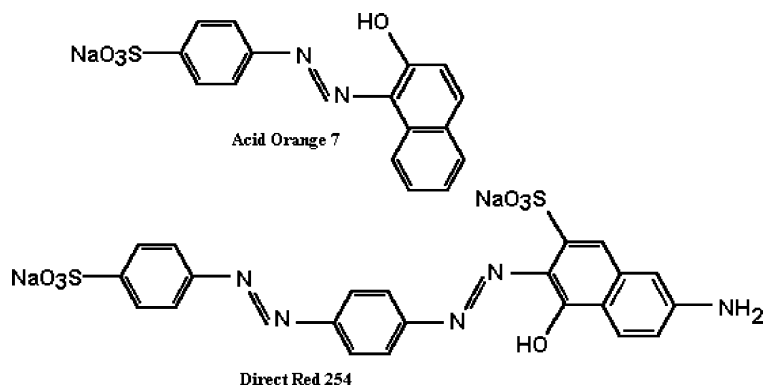

Fig. 1. Chemical structures of the azo dyes used. 
(Orange II) from Sigma Chemical Co. (Germany), sulfanilic acid (SA) and 1-amino-2-naphtol (1A2N) from Aldrich Chem. Co. (Germany), were used as standard compounds.

\section{Results and discussion}

\subsection{Operation at a hydraulic retention time of $24 h$}

The start up period of the methanogenic UASB was carried out by changing the glucose/sucrose carbon source to acetate in the feed of a mixed mesophilic reactor. During this period the reactor was operated with an acetate COD loading rate of $1.8 \pm 0.2 \mathrm{~g} \mathrm{l}^{-1} \mathrm{day}^{-1}$ and a HRT of $24 \mathrm{~h}$. Within 50 days, a stable COD removal higher than $85 \%$ was obtained.

After reaching steady-state conditions the monoazo dye, $\mathrm{AO} 7$, was supplemented to the feed at several concentrations $\left(60,100,150\right.$ and $\left.300 \mathrm{mg} \mathrm{l}^{-1}\right)$. As the influent dye concentration was increased an increase in the total COD levels in the treated effluent was observed, leading to a decrease of the overall COD removal from $92 \pm 3 \%$ at $60 \mathrm{mgl}^{-1}$, to $67 \pm 2 \%$ at $300 \mathrm{mg} \mathrm{l}^{-1}$, for AO7 (Fig. 2). However, this does not seem to indicate an inhibitory effect of $\mathrm{AO} 7$ on the organic load removal since the apparent acetate-based COD removal yield remains approximately constant (Fig. 3), even at high fed dye concentration $\left(300 \mathrm{mg} \mathrm{l}^{-1}\right)$. This apparently indicates that the contribution of the dye or dye metabolites to the influent and effluent COD is almost the same, and the residual COD could be attributed essentially to the dye or its metabolites. Furthermore, according to the activity assays performed with methanogenic sludge taken from the UASB, the presence of dye in the basal medium does not significantly affect the metabolic activity. The specific methanogenic activity was, in average, of $1.31 \pm 0.031 \mathrm{~g}^{-1} \mathrm{day}^{-1}$ for AO7 concentrations up to $1800 \mathrm{mg} \mathrm{l}^{-1}$, which is not significantly different from the value obtained in dye-free conditions $(1.2 \pm$ $\left.0.1 \mathrm{~g} \mathrm{~g}^{-1} \mathrm{day}^{-1}\right)$. The biogas production was also not altered by the dye fed to the reactor in concentrations up to $300 \mathrm{mg} \mathrm{l}^{-1}$, as well as the biogas composition (on average $61 \%$ of methane and $36 \%$ of carbon dioxide).

Although colour removal yields were in general higher than those for COD removal (Fig. 2), the former decreased from $92 \pm 2 \%$ at $60 \mathrm{mg} \mathrm{l}^{-1}$, to $85 \pm 4 \%$ at $300 \mathrm{mg} \mathrm{l}^{-1}$, indicating an increase of the residual dye concentration in the treated effluent. UV-visible spectra obtained for clarified samples taken at the UASB reactor inlet and outlet, showed marked alterations, as exemplified in Fig. 4A, which could be explained by structural modification of the dye molecule.

The identification of sulfanilic acid and 1-amino-2naphtol, as anaerobic dye metabolites was attempted with HPLC analysis of filtered UASB samples through comparison with standard compounds. Although the chromatogram obtained for the AO7 feed shows three peaks, at retention times of 1.9, 20.6 and $25.1 \mathrm{~min}$ (Fig. 5A), only the one at $20.6 \mathrm{~min}$ corresponds to the dye molecule, as concluded from the chromatogram

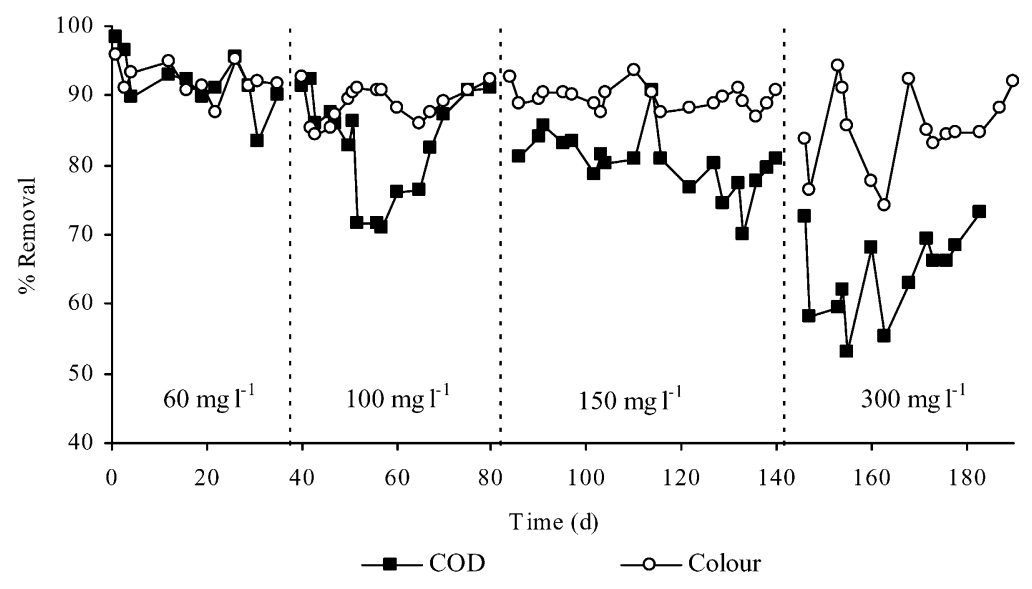

Fig. 2. COD and colour removal in the UASB operated at $24 \mathrm{~h}$ HRT and fed with several AO7 concentrations (indicated for each period). 


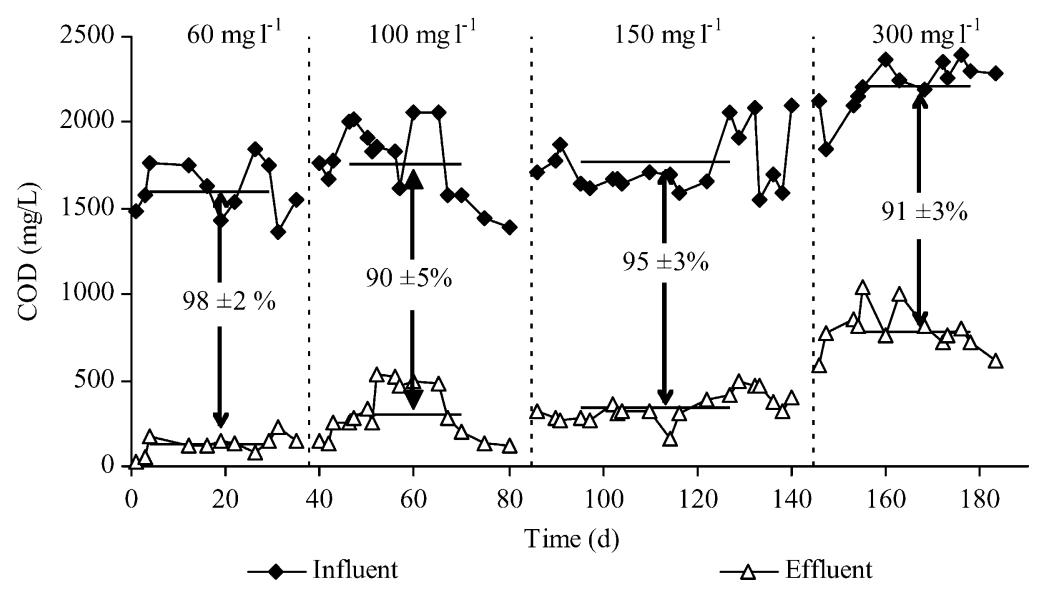

Fig. 3. COD concentrations in samples from the UASB operated at $24 \mathrm{~h}$ HRT and fed with several AO7 concentrations (indicated for each period). The given $\%$ values are average COD removal levels on the basis of the fed acetate COD load.
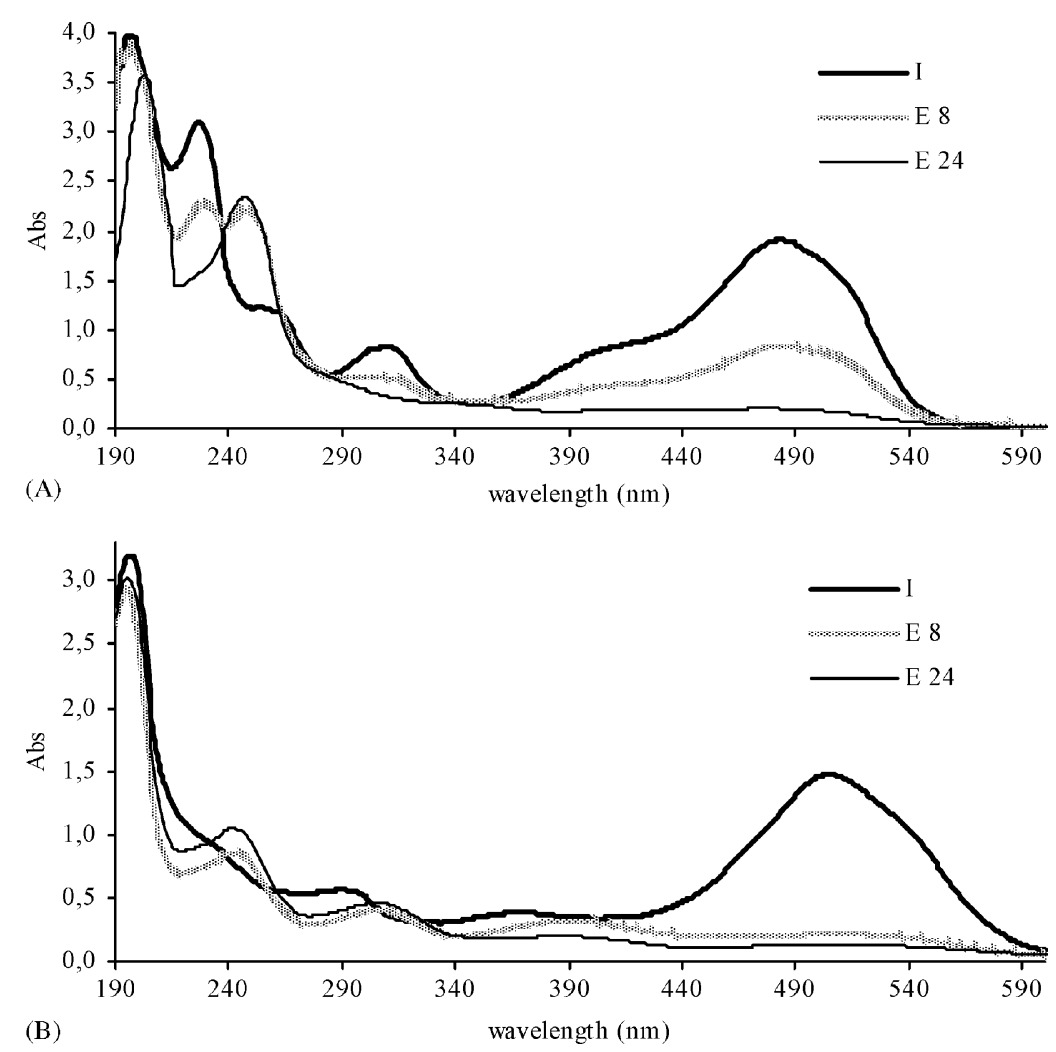

Fig. 4. UV-visible spectra obtained for filtered samples from the methanogenic UASB reactor on treating AO7 (A) and DR254 (B) at $150 \mathrm{mg} 1^{-1}$ (I, influent; E 8, effluent at $8 \mathrm{~h}$ HRT; E 24, effluent at $24 \mathrm{~h}$ HRT). 


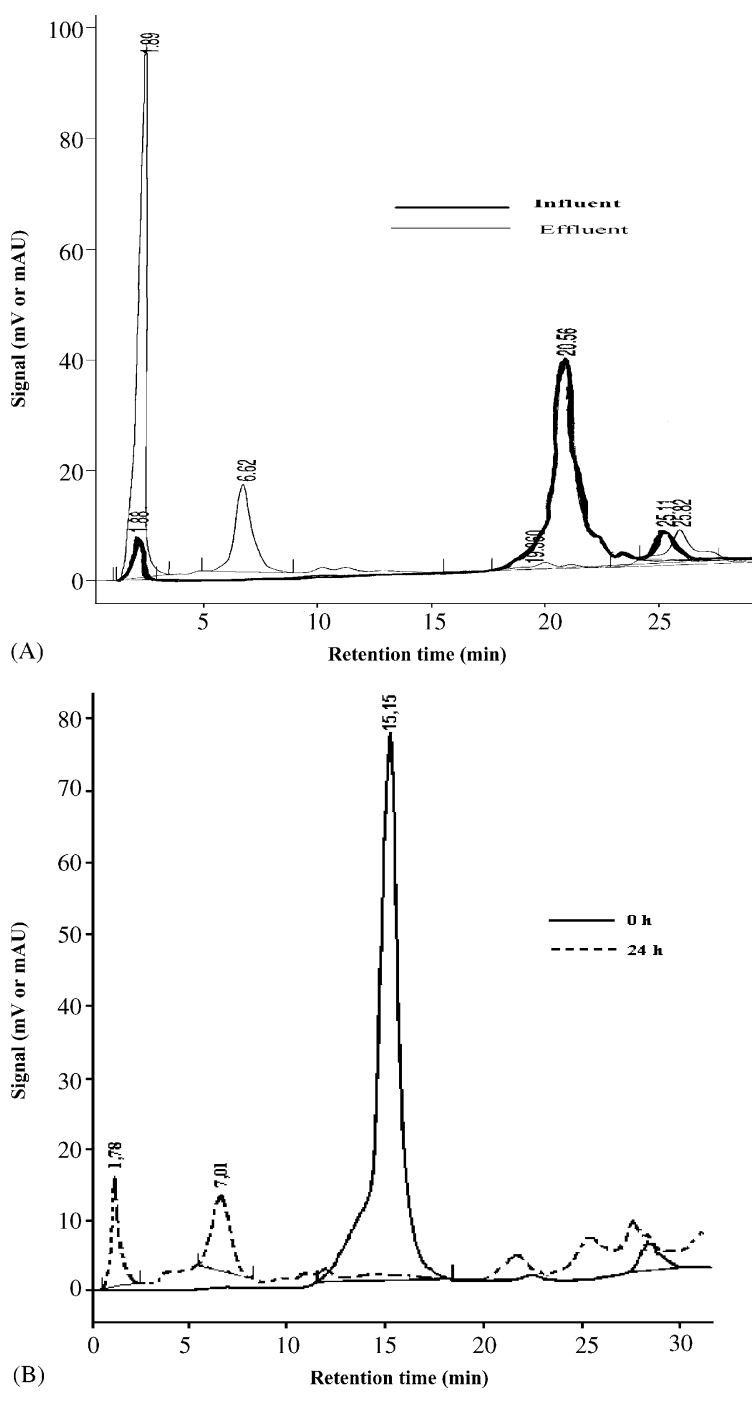

Fig. 5. Chromatograms obtained for filtered samples taken from the UASB reactor fed with $\mathrm{AO} 7\left(60 \mathrm{mg} \mathrm{l}^{-1}\right)$ at $24 \mathrm{~h} \mathrm{HRT} \mathrm{(A)} \mathrm{and} \mathrm{in}$ aeration tests of $1 \mathrm{~A} 2 \mathrm{~N}$ standards solutions at different times (B).

obtained with the purified dye form. The first peak (at 1.9 min) obtained for the $\mathrm{AO} 7$ commercial dye solution was identified as sulfanilic acid, which is used as precursor in the $\mathrm{AO} 7$ synthesis process. The high intensity of this signal for the UASB effluent, reported in Fig. 5A, indicates the presence of sulfanilic acid, probably due to the anaerobic azo bond reduction of AO7. These results confirm the structural modifications suggested by the UV-visible spectra changes, and also show that the sulfanilic acid still remains in the treated effluent, i.e., is not anaerobically mineralised.

In an attempt to identify the presence of 1-amino2-naphtol $(1 \mathrm{~A} 2 \mathrm{~N})$, as another anaerobic breakdown product, chromatograms of UASB effluent samples and standard solutions of $1 \mathrm{~A} 2 \mathrm{~N}$ were compared. Results indicate that the main peak obtained at $15.1 \mathrm{~min}$ for the standard $1 \mathrm{~A} 2 \mathrm{~N}$ is not present in samples taken from the anaerobic reactor (Fig. 5), suggesting 1A2N degradation. However, it has been reported (Kudlich et al., 1999) that auto-oxidation of $1 \mathrm{~A} 2 \mathrm{~N}$ can occur in the presence of oxygen. Tests with $1 \mathrm{~A} 2 \mathrm{~N}$ standard solutions in aeration conditions revealed marked chemical structural changes in time (Fig. 5B), which are possibly due to the auto-oxidation process. This could also help to understand the chromatograms obtained in samples taken from the UASB outlet. As those samples were previously filtered in aerated conditions, the peak observed at $6.6 \mathrm{~min}$ (Fig. 5A) is attributed to a compound resulting from $1 \mathrm{~A} 2 \mathrm{~N}$ auto-oxidation, which can be concluded by examining Fig. 5A and B. This peak also indicates that this metabolite is not degraded in the anaerobic bioreactor where it remains in the original form, since inside the reactor lower redox potential conditions are prevailing. Essays performed at $\mathrm{pH} 4.4$ with standard solutions showed that the peak at $15.5 \mathrm{~min}$ remained constant during the aeration time, meaning that the compound does not undergo auto-oxidation in these conditions.

The anaerobic degradation of the diazo dye, DR254, was studied after running the reactor on the same acetate-based feed for 20 days with no dye addition. Results show higher COD and colour removal yields for DR254 than for AO7 (Fig. 6). The lower contribution of the DR254 to the total COD $\left(1.3 \mathrm{~g} \mathrm{COD} \mathrm{g}^{-1}\right.$ dye $)$ relatively to $\mathrm{AO} 7$ (2.2 $\mathrm{g} \mathrm{COD} \mathrm{g}^{-1}$ dye) could simply explain these higher COD removal levels. The presence of formic acid included in the AO7 formulation also contributes to the higher COD values obtained for this type of dye solutions. Moreover, the theoretical oxygen demand is still higher for $\mathrm{AO} 7\left(1.6 \mathrm{~g} \mathrm{COD} \mathrm{g}^{-1}\right.$ dye) than for DR254 (1.2 $\mathrm{g} \mathrm{COD} \mathrm{g}^{-1}$ dye). Structural differences between the dye molecules (Fig. 1) probably influence their affinity for the biomass, leading to a better DR254 colour removal. However, as can be seen in Fig. 4, significant spectral changes also occur for DR254, indicating molecular modifications rather than adsorption onto the biomass. 

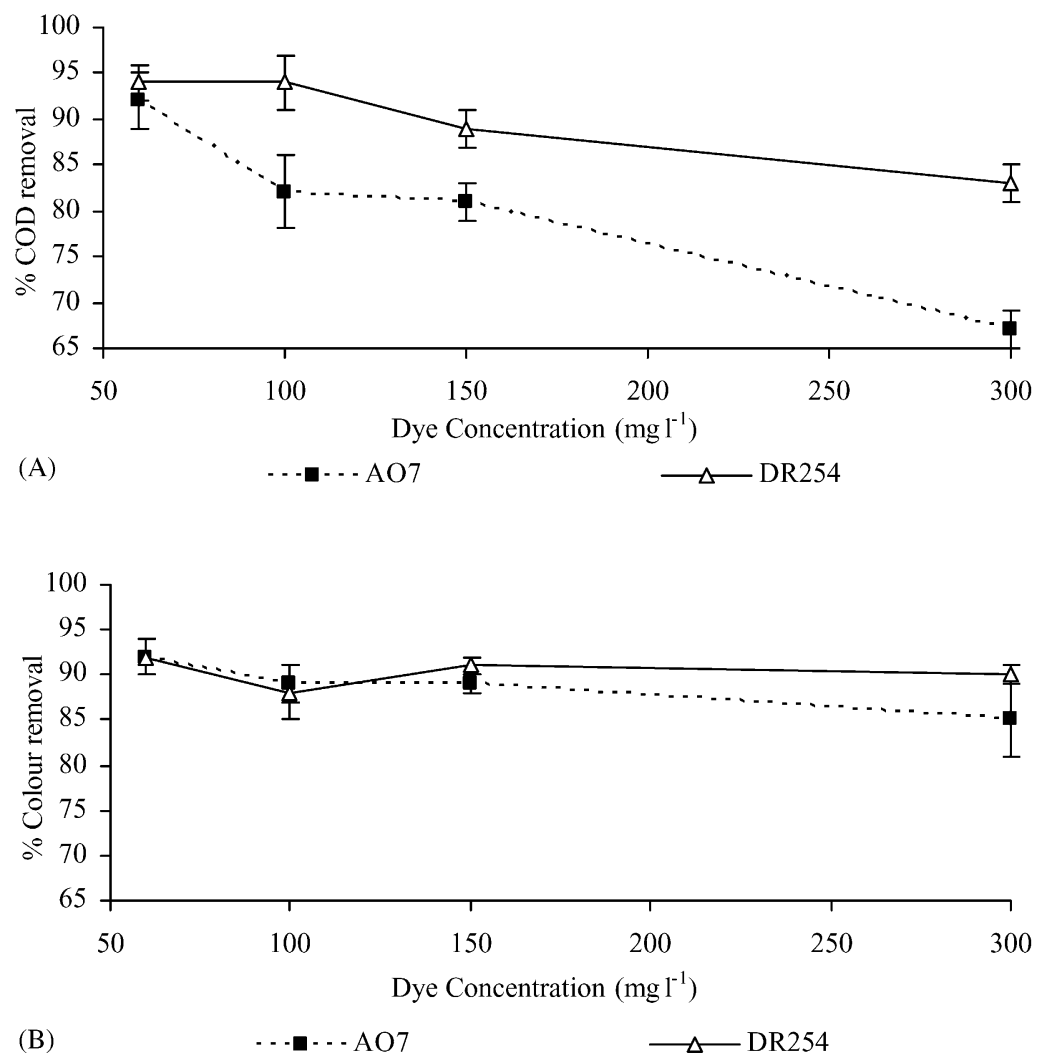

Fig. 6. COD (A) and colour (B) removal in the UASB reactor operated at $24 \mathrm{~h}$ HRT for the AO7 and DR254 at different fed concentrations.

Specific methanogenic activity tests with UASB sludge also showed that the presence of the dye DR254 does not alter significantly the metabolic activity. Methanogenic activity levels around $1.29 \pm$ $0.07 \mathrm{gg}^{-1} \mathrm{day}^{-1}$, were measured for dye concentrations up to $1800 \mathrm{mgl}^{-1}$, similar to those attained in tests without dye.

\subsection{Operation at a hydraulic retention time of $8 \mathrm{~h}$}

To assess the effect of the hydraulic retention time (HRT) on reactor performance, experiments with the UASB operating with $8 \mathrm{~h}$ HRT were carried out. The results in Fig. 7, at fed dye concentrations of 60 and $150 \mathrm{mg}^{-1}$, show a lower COD removal for the monoazo dye, AO7, as previously reported for the UASB operation at $24 \mathrm{~h} \mathrm{HRT}$. This difference is significantly enhanced for decolourisation levels, particularly at $150 \mathrm{mg} \mathrm{l}^{-1}$ of fed dye (Fig. 7B), for which colour removal yields of only $56 \pm 3 \%$ for $\mathrm{AO} 7$ and $82 \pm 3 \%$ for DR254 were achieved, indicating a lower efficiency of azo bond reduction in the reactor.

COD profiles obtained for samples taken along the height of the UASB support the idea that the acetate COD removal yield is not significantly altered by the presence of the dye (Fig. 8A). Also a faster colour removal rate relatively to COD removal is observed, indicating that azo bond reduction occurs in the first two sample ports (in the first $20 \mathrm{~cm}$ height) simultaneously with the primary carbon source (acetate) degradation. This means that the amount of carbon source necessary to produce the equivalent reducers to decolourise azo dyes is indeed very low. The acetate degradation apparently occurs essentially in the first half height $(30-40 \mathrm{~cm})$ of the reactor, in which most of the biomass is located (the sludge bed occupies 30-40\% (v/v) approximately. Even at a HRT of $8 \mathrm{~h}$, high levels of acetate COD removal were achieved in the presence of 

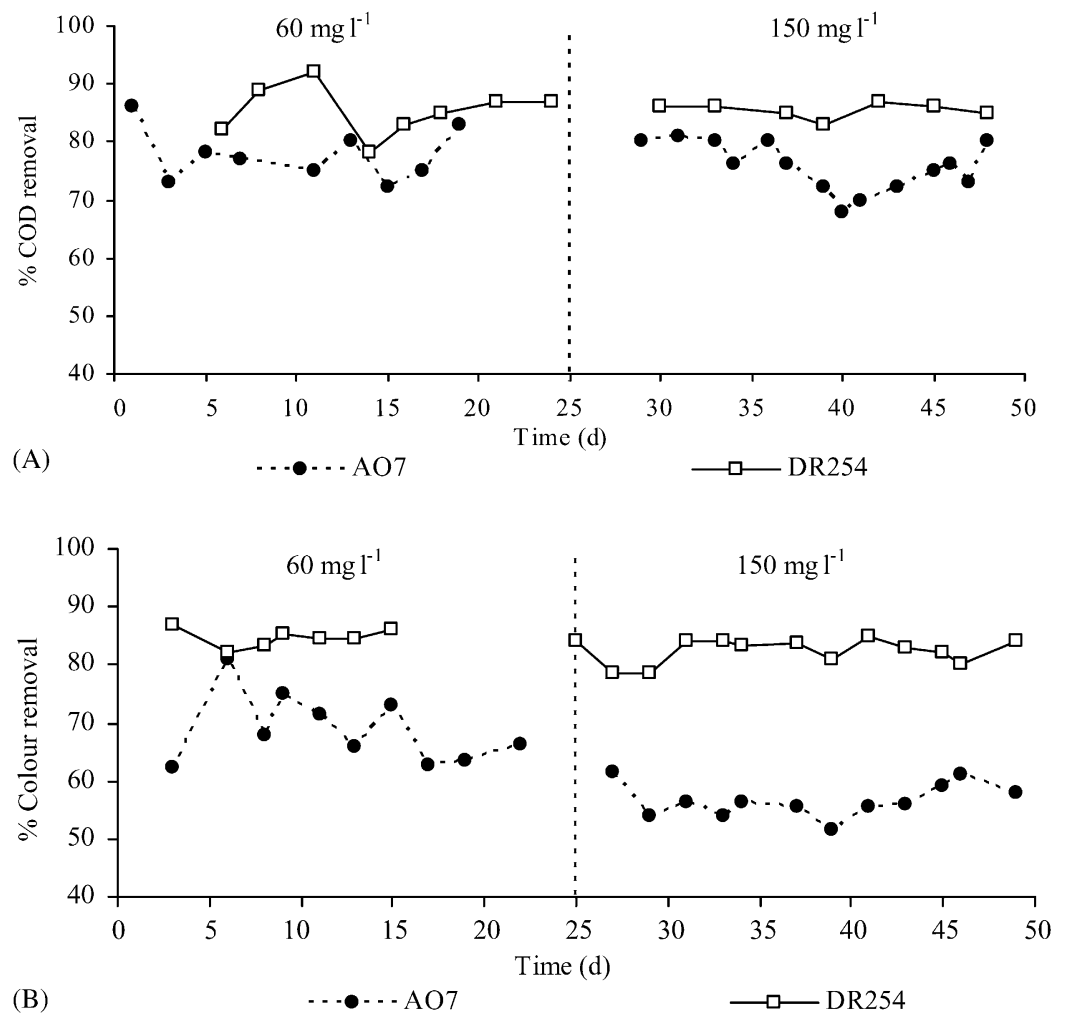

Fig. 7. COD (A) and colour (B) removal in the UASB operated at $8 \mathrm{~h}$ HRT with two AO7 and DR254 fed concentrations.

both dyes. UV-visible spectra (Fig. 4A) taken at $8 \mathrm{~h}$ HRT with fed AO7 show a smaller decrease in the peak observed at the maximum absorbance wavelength $(482 \mathrm{~nm})$ than for $24 \mathrm{~h}$ HRT. HPLC analyses confirm the presence of dye in the treated effluent and indicate a reduction in the sulfanilic acid yield of about 53\%, relatively to that obtained with $24 \mathrm{~h}$ HRT. Although a slight decrease in the colour removal yield was also observed for the diazo dye DR254, an overall better performance of the UASB with this dye was noticed.

The less extensive reductive biotransformation of AO7 is not explained simply by taking into account the size of the molecules and the number of azo bonds (Fig. 1). According to Bracko and Span (1996), there is an aggregation process of $\mathrm{AO} 7$ molecules in the presence of an electrolyte, which occurs even at low concentrations, leading to dye dimerization. Hydrogen bonds, electrostatic interactions and mainly van der Waals' forces and hydrophobic interactions influence the aggregation of anionic dyes. The affinity be- tween two dye anions can be high enough to overcome electrostatic repulsion. Furthermore, aggregation depends on how planar the molecule is, on the number of conjugated double bonds and on the location of sulfonic groups (Cegara et al., 1992). Aggregation increases with higher dye concentration and medium ionic strength. In our experiments, azo dyes were dissolved in a basal medium, which contained ions in significant concentration, so the aggregation can be favoured for both dye molecules, though at different levels. In spite of the fact that the DR254 molecule has a linear structure, favouring dye-dye aggregation, it has two bulky sulfonic groups, one of which located close to one of the azo bonds, which probably reduces the aggregation tendency. On the contrary, the sole sulfonic group of $\mathrm{AO} 7$ is located at the periphery of the molecule, favouring its self-association and leading to a decrease of dye availability for anaerobic reduction. This effect could explain the colour removal profiles of Fig. 8B. Decolourisation roughly follows 

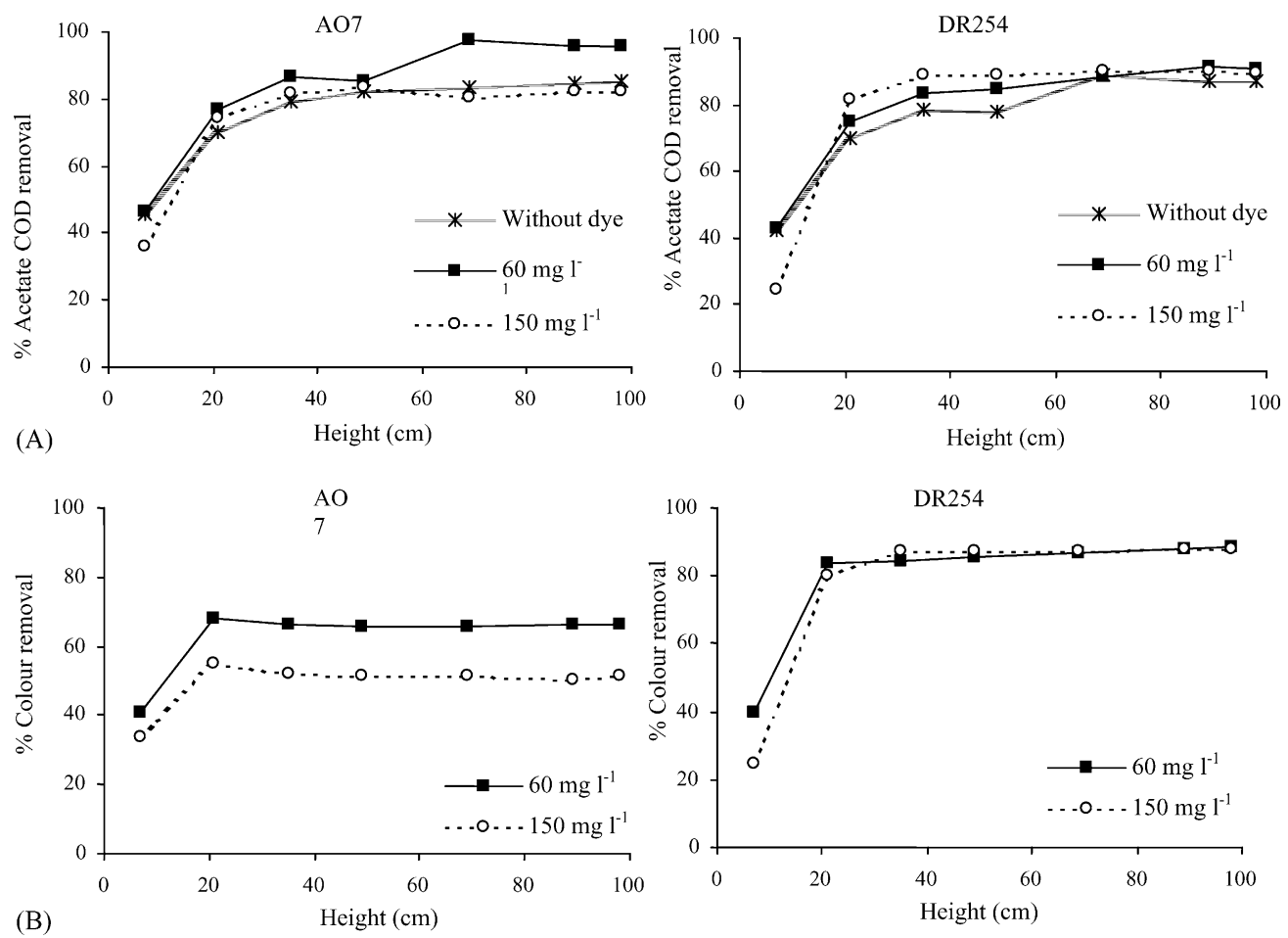

Fig. 8. Profiles of COD (A) and colour (B) removal for UASB reactor operated at $8 \mathrm{~h}$ HRT for the AO7 and DR254 at different fed concentrations.

the COD removal profiles, but would be limited to the non-aggregate fraction of the dye in solution, this being greater for DR254 than for AO7. With a HRT of $24 \mathrm{~h}$, the slower decolourisation of the aggregated dye could possibly occur to a higher extent, giving the observed higher removal yields for both dyes.

\section{Conclusions}

The results presented in this study demonstrate that it is possible to obtain high decolourisation yields of azo dyes (85-92\%) in a methanogenic UASB reactor with a high level of acetate degradation. COD removal rates decrease with the increase in fed dye concentration (from $92 \pm 3 \%$ at $60 \mathrm{mgl}^{-1} \mathrm{AO} 7$ to $67 \pm 2 \%$ at $300 \mathrm{mg}^{-1} \mathrm{AO} 7$ at $24 \mathrm{~h} \mathrm{HRT}$ ) and results obtained from HLPC analyses and UV-visible spectrophotometry indicate that residual dyes and its metabolites are still present in the treated effluent, thus contributing to the total COD. Acetate degradation seems not to be affected by the presence of dyes and its breakdown products. Specific UASB sludge methanogenic activity levels obtained in batch assays with both dyes, in concentrations up to $1.8 \mathrm{~g} \mathrm{l}^{-1}$, support this conclusion.

In general, the results show higher decolourisation yields for the diazo dye DR254. Probably, the aggregation process associated to a low molecular diffusion rate of the species involved, could explain the lower colour removal yields attained for AO7 at a HRT of $8 \mathrm{~h}$. Chemical structures influence the dye aggregation process and therefore the availability of dyes to the methanogenic consortium, altering the rate of aromatic amine production. Further research is required on this subject, in order to understand all the factors influencing the reductive cleavage of dyes in anaerobic environments.

\section{Acknowledgements}

Authors would like to acknowledge the research fund of the grant PRAXIS XXI BD/15670/98 and of the project POCTI/1999/EQU/32456 supported by the 
Fundação para a Ciência e Tecnologia (FCT). They also would like to thank Dr. Nídia Lourenço of Instituto Superior Técnico for technical help with the liquid chromatography.

\section{References}

APHA, AWWA, WPCF, 1992. R. Trussel (Ed.), Standard Methods for the Examination of Water and Wastewater, 19th ed., Washington, USA.

Bracko, S., Span, J., 1996. Osmotic coefficients of C.I. Acid Orange 7 in aqueous solution and in presence of simple electrolyte. Dyes Pigments 35 (2), 165-169.

Brás, R., Ferra, M.I.A., Pinheiro, H.M., Gonçalves, I.C., 2001. Batch tests for assessing decolourisation of azo dyes by methanogenic and mixed cultures. J. Biotechnol. 89, 155-162.

Brown, D., Hamburguer, B., 1987. The degradation of dyestuffs. Part III. Investigations of their ultimate degradability. Chemosphere $16,1539-1553$.

Carliell, C.M., Barclay, S.J., Buckley, C.A., 1996. Treatment of exhausted reactive dyebath effluent using anaerobic digestion: laboratory and full-scale trials. Water SA 22 (3), 233-275.

Cegara, J., Puente, P., Valldeperas, J., 1992. The Dyeing of Textile Materials: The Scientific Bases and the Techniques of Application, 2 ed. Texilia, Rome.

Donlon, B.A., Razo-Flores, E., Luijten, M., Swarts, H., Lettinga, G., Field, J., 1997. Toxicity of $N$-substituted aromatics to acetoclastic methanogenic activity in granular sludge. Appl. Microbiol. Biotechnol. 47, 83-90.
Kudlich, M., Hetheridge, M.J., Knackmuss, H.J., Stolz, A., 1999. Auto-oxidation reactions of different aromatic oaminohydroxynaphtalene that are formed during the anaerobic reduction of sulfonated azo dyes. Environ. Sci. Technol. 33, 896-901.

Lettinga, G., van Velsen, A.F.M., Hobma, S.W., de Zeeuw, W., Klapwijk, A., 1980. Use of the upflow sludge blanket (USB) reactor concept for biological treatment, especially for anaerobic treatment. Biotechnol. Bioeng. 22, 699-734.

Lettinga, G., Field, J.A., Sierra, R., van Lier, J.B., Rintala, J., 1991. Futures perspectives for the anaerobic treatment of forestry industry wastewaters. Wat. Sci. Technol. 224, 91-102.

McInerney, M.J., Bryant, M.P., Stafford, A., 1980. Metabolic stages and energetics of microbial anaerobic digestion. In: Stafford, D.A., Wheatley, B.I., Hughes, D.E. (Eds.), Anaerobic Digestion. Applied Science Publishers, London, pp. 91-98.

Pasti-Grigsby, M.B., Paszcynski, A., Goszczynski, S., Crawford, D.L., Crawford, R.L., 1992. Influence of aromatic substitution patterns on azo dye degrability by Streptomyces spp. and Phanerochaete chrysosporium. Appl. Environ. Microbiol., 3605-3613.

Razo-Flores, E., Donlon, B.A., Field, J.A., Lettinga, G., 1996. Biodegradability of $\mathrm{N}$-substituted aromatics and alkylphenols under methanogenic conditions using granular sludge. Wat. Sci. Technol. 33 (3), 47-57.

Stronach, S.M., Rudd, T., Lester, J.N., 1986. Anaerobic digestion processes in industrial wastewater treatment. In: Biotechnology Monographs. Springer-Verlag, Berlin.

Wuhrmann, K., Mechsner, K., Kappeler, T., 1980. Investigation on rate-determining factors in the microbial reduction of azo dyes. Eur. J. Appl. Microbiol. Biotechnol. 9, 325-338.

Zollinger, H., 1987. Color Chemistry: Syntheses, Properties and Applications of Organic Dyes and Pigment. VCH, NY. 